\title{
Revisão sistemática sobre carnes salgadas e seus processos de qualidade
}

\author{
Systematic review of salted meat and its quality processes \\ Revisión sistemática de la carne salada y sus procesos de calidad
}

Recebido: 27/10/2021 | Revisado: 06/11/2021 | Aceito: 15/11/2021 | Publicado: 24/11/2021

\author{
Pedro Abreu da Silva Neto \\ ORCID: https://orcid.org/0000-0002-6916-8712 \\ Instituto Federal de Educação Ciência e Tecnologia do Ceará, Brasil \\ E-mail: pabreunt@gmail.com \\ Felipe Kairo de Sousa Lima \\ ORCID: https://orcid.org/0000-0001-6728-3007 \\ Instituto Federal de Educação Ciência e Tecnologia do Ceará, Brasil \\ E-mail: felipe.kairo03@aluno.ifce.edu.br \\ Luana Guabiraba Mendes \\ ORCID: https://orcid.org/0000-0001-8184-8588 \\ Universidade Federal do Ceará, Brasil \\ E-mail: luanagmendes@gmail.com \\ Antônia Lucivânia de Sousa Monte \\ ORCID: https://orcid.org/0000-0003-2504-5136 \\ Instituto Federal de Educação Ciência e Tecnologia do Ceará, Brasil \\ E-mail: lucivania@ifce.edu.br
}

\begin{abstract}
Resumo
Esta pesquisa consiste em uma revisão sistemática desenvolvida com base em estudos sobre a origem e os processos de evolução das carnes salgadas, assim como, sobre os atuais parâmetros de qualidade praticados pelo setor industrial e artesanal no que diz respeito a este produto. O Regulamento da Inspeção Industrial e Sanitária de Produtos de Origem Animal (RIISPOA) define como carne salgada todo e qualquer produto comestível, preparado a base de carnes ou órgãos, tratados por meio de cloreto de sódio, ou da mistura de outros sais com nitratos, nitritos, condimentos e açúcares. Para tanto, este estudo visa resgatar por meio de uma revisão sistemática, a literatura, a historicidade e a evolução das carnes salgadas no Brasil e seus parâmetros de qualidade. As pesquisas analisadas para compor esta revisão sistemática foram consultadas nas seguintes bases de dados online: Scielo (Scientific Eletronic Library Online), Periódicos da Capes e Science Direct, através da utilização dos seguintes termos de busca: "Carnes Salgadas" "Carne de Charque", "Carne de Sol", "Qualidade da Carne", "Microbiologia" e "Beef jerky". O período definido para a inclusão das pesquisas publicadas foi delimitado entre os anos de 2010 a setembro de 2021. As buscas iniciais nas bases de dados online indicaram um total de 637 trabalhos sobre o tema de carnes salgadas, encontrados a partir da utilização das palavras-chave. Ao delimitar o tempo de produção entre os anos de 2010 a 2021 obtivemos um total de 136 artigos relacionados, os quais foram analisados através de seus títulos e resumos, resultando um total de 32 artigos encontrados. Sob a proposta de identificar aqueles que possuíam uma relação direta com o tema central desta pesquisa, estudou-se referentes metodologias. Portanto, foram selecionados de forma objetiva e criteriosa 17 artigos para compor esta revisão sistemática. Considerando a análise realizada em todo levantamento bibliográfico, seja sob parâmetros históricos, tecnológicos ou gastronômicos, é possível visualizar o impacto histórico e tecnológico que este alimento possui no decorrer de seu desenvolvimento, além de verificar um avanço nas técnicas de produção e qualidade das carnes salgadas.
\end{abstract}

Palavras-chave: Tecnologia de carnes; Historicidade; Carnes secas.

\begin{abstract}
This research consists of a systematic review developed based on studies of the origin and evolution processes of salted meat, as well as the quality parameters practiced by the industrial and artisanal sector concerning this product. O Regulamento da Inspeção Industrial e Sanitária de Produtos de Origem Animal (RIISPOA) defines as salted meat any edible product, prepared based on meat or organs, treated with sodium chloride, or by mixing other salts with nitrates, nitrites, spices, and sugars. Therefore, this study aims to rescue, through a systematic review, the literature, history, and evolution of salted meat in Brazil and its quality parameters. The surveys analyzed to compose this systematic review were consulted in the following online databases: Scielo (Scientific Electronic Library Online), Periodico Capes, and Science Direct, using the following search terms: "Carnes Salgadas" "Carne de Charque", "Carne de Sol", "Qualidade da Carne", "Microbiologia" e "Beef jerky". The period defined for the inclusion of published research was delimited between the years 2010 to September 2021. Initial searches in online databases indicated a total of 637 works on the subject of salted meat, found using the words- key. By delimiting the production time between the years 2010 to 2021 , we obtained a total of 136 related articles, which were published through their
\end{abstract}


titles and abstracts, discovering a total of 32 articles found. To identify those who had a direct relationship with the central theme of this research, the methodologies were studied. Therefore, 17 articles were objectively and carefully selected to compose this systematic review. To characterize an analysis carried out in every bibliographic survey, whether under historical, technological, or gastronomic parameters, it is possible to visualize the historical and technological impact that this food has no progress in its development, in addition to verifying an advance in production techniques and quality of salted meats.

Keywords: Meat technology; Historicity; Dried meats.

\section{Resumen}

Esta investigación consiste en una revisión sistemática desarrollada a partir de estudios sobre los procesos de origen y evolución de la carne salada, así como de los parámetros de calidad practicados por el sector industrial y artesanal con respecto a este producto. O Regulamento da Inspeção Industrial e Sanitária de Produtos de Origem Animal (RIISPOA) define como carne salada todo producto comestible, elaborado a base de carne o órganos, tratado con cloruro de sodio, o mezclando otros sales con nitratos, nitritos, especias y azúcares. Por lo tanto, este estudio tiene como objetivo rescatar, a través de una revisión sistemática, la literatura, la historia y la evolución de la carne salada en Brasil y sus parámetros de calidad. Las encuestas analizadas para componer esta revisión sistemática fueron consultadas en las siguientes bases de datos en línea: Scielo (Scientific Electronic Library Online), Periodico Capes y Science Direct, utilizando los siguientes términos de búsqueda: "Carnes Salgadas" "Carne de Charque", "Carne de Sol", "Qualidade da Carne", "Microbiologia" e "Beef jerky". El período definido para la inclusión de la investigación publicada se delimitó entre los años 2010 a septiembre de 2021. Las búsquedas iniciales en bases de datos en línea indicaron un total de 637 trabajos sobre el tema de la carne salada, encontrados utilizando la palabra clave. Al delimitar el tiempo de producción entre los años 2010 a 2021, obtuvimos un total de 136 artículos relacionados, los cuales fueron publicados a través de sus títulos y resúmenes, descubriendo un total de 32 artículos encontrados. Con el propósito de identificar a quienes tenían una relación directa con el tema central de esta investigación, se estudiaron las metodologías. Por lo tanto, se seleccionaron 17 artículos de manera objetiva y cuidadosa para componer esta revisión sistemática. Para caracterizar un análisis realizado en cada levantamiento bibliográfico, ya sea bajo parámetros históricos, tecnológicos o gastronómicos, es posible visualizar el impacto histórico y tecnológico que este alimento no tiene avances en su desarrollo, además de constatar un avance en las técnicas de producción y calidad de las carnes saladas.

Palabras clave: Tecnología de la carne; Historicidad; Carnes secas.

\section{Introdução}

De acordo com o Regulamento da Inspeção Industrial e Sanitária de Produtos de Origem Animal (RIISPOA), é definido como carne salgada, todo e qualquer produto comestível, preparado a base de carnes ou órgãos, tratados por meio de cloreto de sódio, ou da mistura de outros sais com nitratos, nitritos, condimentos e açúcares (Brasil, 2020). A carne bovina salgada curada dessecada ou jerked beef é o produto cárneo obtido de carne bovina, com adição de sal e de agentes de cura, submetido a processo de dessecação. Já o Charque é um produto cárneo obtido de carne bovina, com adição de sal e submetido a processo de dessecação. Diversas nomenclaturas são empregadas, dependendo da região país, do tipo de corte da carne, ou do modo de preparo (Brasil, 2020).

As carnes salgadas são amplamente conhecidas em todo mundo, apresentando algumas variações de sabor, vida útil e composição. Mesmo com o avanço da tecnologia de alimentos ao longo dos anos, a salga e a dessecação no processamento de produtos cárneos mantiveram-se (Ishihara; Madruga, 2013).

A salga é conhecida como um dos métodos mais tradicionais para preservação dos alimentos, conferindo a ele propriedades sensoriais especiais, ao mesmo tempo em que se mostra simples e fácil de ser realizada e apresenta baixo custo. (Freitas et al., 2011). A ação do sal, reage sobre as proteínas, reduzindo a atividade de água do produto perdendo a água livre contida nele por osmose (Alves et al., 2010).

As carnes salgadas apresentam suas diferenças através das técnicas de preparo e nas suas diferentes origens. Sobre isto, é relevante saber que o Charque é uma carne de origem do Sul do País, provinda do Rio Grande do Sul, já o Jerked beef é provindo do Nordeste, e pôr fim a Carne-de-sol que tem sua origem mineira (Bonde, 2013). 
O charque é um dos produtos mais tradicionais do Brasil. Surgiu por volta do século XVIII, na região Nordeste, como forma de contornar as dificuldades decorrentes da alta perecibilidade da carne, agravada por fatores como a sazonalidade da oferta de carne bovina e dificuldade da distribuição e armazenamento devido ao clima quente e à grande extensão territorial (Pardi et al, 1996).

Em sua historicidade, observa-se que a grande seca de 1777 no Nordeste afetou a produção local de carnes-secas, levando o charqueador português José Pinto Martins, atraído pela abundância de gado existente nos pampas meridionais, a transferir-se para o Rio Grande do Sul e a fundar a primeira charqueada de pelotas, às margens do arroio homônimo de 1780. Com a implantação desta, a salga das carnes transformou-se numa indústria poderosa que tornou a pecuária a razão da existência das estâncias do interior, principalmente na metade sul rio-grandense (Carvalho Jr, 2002).

No Rio Grande do Sul, as primeiras charqueadas (fábricas de carne-seca) foram instaladas nos fins do século XVIII, surgindo a partir da necessidade de suprir a crescente demanda por alimentos, impulsionada pelo grande fluxo de escravos africanos para a América portuguesa. Além disso, as primeiras charqueadas foram desenvolvidas através dos investimentos de comerciantes que viram nelas uma oportunidade de preencher um espaço aberto com a crise da produção de carne-seca no Nordeste, ocasionada pelas duras secas que afetaram a região. (Osório, 2007).

Sobre os parâmetros de qualidade praticados pelo setor industrial e artesanal, observa-se que, atualmente as etapas de produção estão amplamente amparadas pelos programas e sistemas, que tem por objetivo garantir as condições adequadas de higiene, as quais envolvem desde a aquisição da matéria-prima até a entrega do produto ao consumidor. Todas produções devem ser realidade respeitando certos padrões específicos de higiene, limpeza e segurança e estar em constante avaliação para que possam sinalizar ao consumidor que o alimento é seguro e de qualidade (Cas, 2010).

Para tanto, este estudo visa resgatar por meio de uma revisão sistemática, a literatura, a historicidade e a evolução das carnes salgadas no Brasil e seus parâmetros de qualidade.

\section{Metodologia}

\subsection{Caracterização do estudo}

Esta pesquisa consiste em uma revisão sistemática desenvolvida com base em estudos sobre a origem e os processos de evolução das carnes salgadas, assim como, sobre os atuais parâmetros de qualidade praticados pelo setor industrial e artesanal no que diz respeito a este produto. No campo da pesquisa científica, Linde e Willich (2003) ressaltam que a revisão sistemática é tipo de pesquisa que delimita a literatura como fonte de informações, uma vez que ela fornece resultados que podem ser divergentes ou semelhantes sobre determinada questão de estudo, possibilitando bases fundamentadas para investigações futuras.

\subsection{Estratégia de busca}

Para a busca dos artigos utilizados nesta revisão sistemática, os seguintes termos foram adicionados: "Carne de Charque", "Carne de Sol”, "Carnes Salgadas", "Qualidade da Carne", "Microbiologia" e "Beef jerky". Cabe ressaltar que, foi realizado as combinações das línguas portuguesa e inglesa com o intuito de abranger uma maior coleta de trabalhos para o estudo. As expressões de busca foram consultadas nas seguintes bases de dados online: Scientific Eletronic Library Online (Scielo), Periódicos da Capes e Science Direct. O período definido para a inclusão das pesquisas publicadas foi delimitado entre os anos de 2010 a setembro de 2021 e o período de busca e coleta dos artigos foi realizada no mês de agosto de 2021.

\subsection{Critérios, processo de seleção dos artigos e coleta de dados}


A pesquisa buscou o objetivo de estudo deste artigo "Origem e processo de evolução das carnes salgadas e dos parâmetros de qualidade", seguindo, para a leitura de seus resumos, de maneira a avaliar os que mais se relacionavam com a temática definida. Examinado este aspecto, foi realizada leitura completa dos artigos selecionados para compor o presente estudo.

Para tanto, a aproximação da abordagem da pesquisa com o objeto de estudo deste trabalho se constituiu como um dos critérios de inclusão das pesquisas, juntamente com a verificação das que foram publicadas em periódicos nacionais e internacionais. Os critérios de exclusão se aplicaram às monografias, dissertações, teses e trabalhos publicados em eventos, assim como, as pesquisas que se mostraram ao longo da leitura não conformes com a temática estudada ou que tinham a data fora do período de publicação delimitado.

As buscas iniciais nas bases de dados online indicaram um total de 637 trabalhos sobre o tema de carnes salgadas, encontrados a partir da utilização das palavras-chave. Ao delimitar o tempo de produção entre os anos de 2010 a 2021 obtivemos um total de 136 artigos relacionados, os quais foram analisados através de seus títulos e resumos, aqueles que apresentaram como tema principal o processo de qualidade, foram selecionados, resultando um total de 32 artigos encontrados. Sob a proposta de identificar aqueles que possuíam uma relação direta com o tema central desta pesquisa, estudou-se referentes metodologias. Portanto, foram selecionados de forma objetiva e criteriosa 17 artigos para compor esta revisão sistemática. As etapas percorridas na seleção das pesquisas estão representadas abaixo, na Figura 1.

Figura 1: Etapas de seleção dos artigos na revisão sistemática.

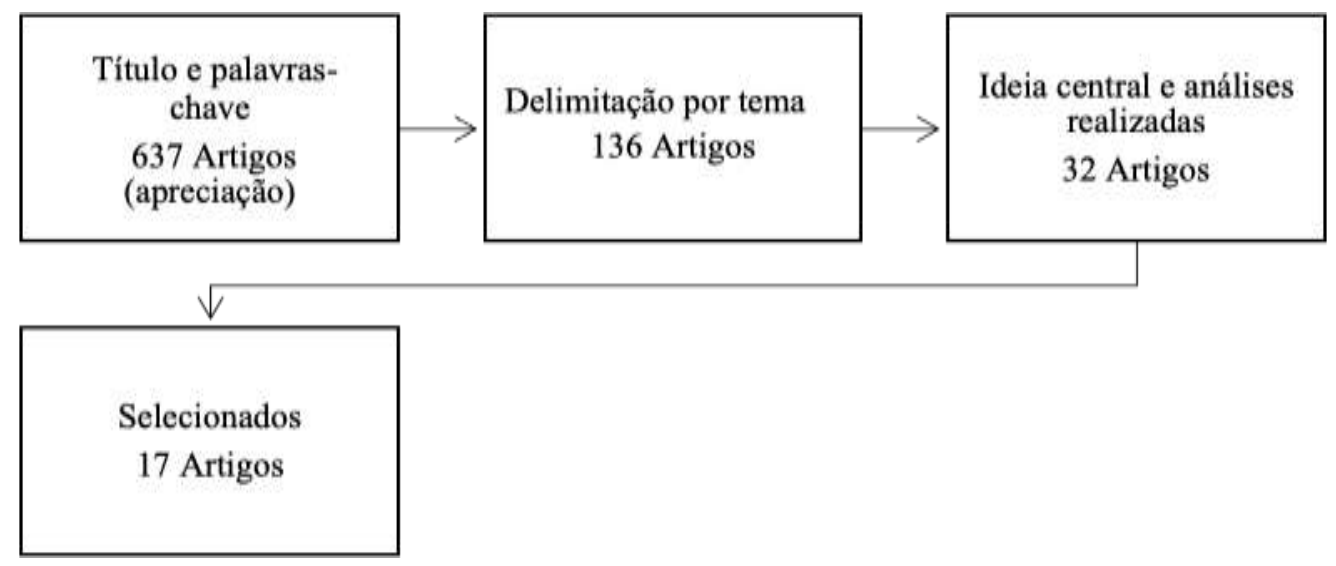

Fonte: Autores (2021).

Na tabela abaixo, (Tabela 1) pode ser verificada as principais informações sobre os 17 artigos selecionados nas bases de dados online Scielo (Scientific Eletronic Library Online), Periódicos da Capes e Science Direct. Em sua estrutura, a tabela traz a quantidade de artigos delimitados, os títulos dos trabalhos, os repositórios em que podem ser encontrados, assim como, a referência dos autores e ano de publicação. Em análise da tabela construída, foram escolhidos 7 artigos da plataforma online Scielo, 6 encontrados nos Periódicos da Capes e 2 no Science Direct, tal como podemos observar a seguir. 
Tabela 1: Artigos selecionados para a revisão sistemática.

\begin{tabular}{|c|c|c|c|}
\hline \multicolumn{4}{|c|}{ Artigos } \\
\hline ID & Título do Artigo & Repositório & Referência \\
\hline Q1 & $\begin{array}{l}\text { Avaliação física-química e microbiológica da carne soleada do } \\
\text { pantanal }\end{array}$ & Scielo & $\begin{array}{l}\text { Alves, Larissa Lima } \\
\text { (2010) }\end{array}$ \\
\hline Q2 & $\begin{array}{l}\text { Avaliação microbiológica de carne de charque produzida } \\
\text { industrialmente }\end{array}$ & Scielo & $\begin{array}{c}\text { Abrantes, Maria Rociene } \\
\text { (2014) }\end{array}$ \\
\hline Q3 & $\begin{array}{l}\text { Avaliação sensorial da carne de sol comercializada nas } \\
\text { cidades de caicó e currais novos }\end{array}$ & Periódicos Capes & $\begin{array}{l}\text { Amaral, denise silva } \\
\text { (2014) }\end{array}$ \\
\hline Q4 & Características físico-químicas del charqui de llama & Scielo & Mamani Linares (2011) \\
\hline Q5 & $\begin{array}{l}\text { Características fisicoquímicas de charque de bovinos (Bos taurus) } \\
\text { y caballo (Equus caballus) }\end{array}$ & Scielo & Mamani Linares (2014) \\
\hline Q6 & $\begin{array}{l}\text { Caracterização microbiológica, físico-química e das condições de } \\
\text { produção e comercialização da carne de sol de salinas, minas } \\
\text { gerais }\end{array}$ & Scielo & $\begin{array}{l}\text { Assis, DCS } \\
\text { (2019) }\end{array}$ \\
\hline Q7 & $\begin{array}{l}\text { Characterisation of flavour profile of beef jerky inoculated with } \\
\text { different autochthonous lactic acid bacteria using electronic nose } \\
\text { and gas chromatography-ion mobility spectrometry }\end{array}$ & Science Direct & $\begin{array}{l}\text { Rongxin Wen } \\
\text { (2021) }\end{array}$ \\
\hline Q8 & $\begin{array}{l}\text { O mercado atlântico das carnes secas e salgadas e a influência da } \\
\text { matriz irlandesa de fabricação no extremo sul da américa latina } \\
\text { (c. } 1780 \text { - c. 1820) }\end{array}$ & Periódicos Capes & $\begin{array}{l}\text { Vargas, Jonas Moreira } \\
\text { (2017) }\end{array}$ \\
\hline Q9 & $\begin{array}{l}\text { Qualidade microbiológica de cortes cárneos utilizados para } \\
\text { elaboração de carne de sol no norte de minas gerais submetidos a } \\
\text { diferentes tecnologias de conservação }\end{array}$ & Periódicos Capes & $\begin{array}{l}\text { Souza, Daniela Ribeiro de } \\
\qquad(2015)\end{array}$ \\
\hline Q10 & $\begin{array}{l}\text { Um método de secagem rápida para a produção de carne salgada } \\
\text { e seca }\end{array}$ & Scielo & $\begin{array}{l}\text { Bampi, Marlene } \\
\text { (2019) }\end{array}$ \\
\hline Q11 & $\begin{array}{l}\begin{array}{l}\text { Avaliação físico-química e microbiológica de carne seca } \\
\text { (charque) }\end{array}\end{array}$ & Roca & $\begin{array}{l}\text { Santos, Angela Maria de Lima dos e } \\
\text { Hentges, Leila Cristina. (2015) }\end{array}$ \\
\hline Q12 & $\begin{array}{l}\text { Charqueada: A História da carne de sol no Ceará e sua frota do } \\
\text { Icó ao Aracati }\end{array}$ & Periódico Capes & $\begin{array}{l}\text { Leandro Flavio Restrepo Frota } \\
\text { Leopoldo Gondim Neto } \\
\qquad(2016)\end{array}$ \\
\hline Q13 & $\begin{array}{l}\text { Implantação das boas práticas de fabricação na indústria de } \\
\text { charque }\end{array}$ & Lume & $\begin{array}{l}\text { Ferreira, Mauren de Chiaro } \\
\qquad(2015)\end{array}$ \\
\hline Q14 & $\begin{array}{l}\text { Effects of } 17 \text { performance, carcass and raw ham quality } \\
\text { parameters on ham weight loss at first salting in heavy pigs, a } \\
\text { meat quality indicator for the production of high quality dry-cured } \\
\text { hams }\end{array}$ & Periódicos Capes & $\begin{array}{l}\text { Stefania Dall'Olio } \\
\text { (2020) }\end{array}$ \\
\hline Q15 & $\begin{array}{l}\text { Phosphorus supplementation does not affect the intake, } \\
\text { digestibility, and meat quality of Nellore young bulls fed with } \\
\text { high-grain diets }\end{array}$ & Periódicos Capes & $\begin{array}{l}\text { Laís de Oliveira Lima } \\
\qquad(2020)\end{array}$ \\
\hline Q16 & $\begin{array}{l}\text { Avaliação dos métodos de conservação de carnes bovinas } \\
\text { salgadas e análise microbiológica }\end{array}$ & Periódicos Capes & $\begin{array}{c}\text { Dos Santos, Juliana Carina } \\
\text { (2017) }\end{array}$ \\
\hline Q17 & $\begin{array}{l}\text { Substituting sodium by various metal ions affects the cathepsins } \\
\text { activity and proteolysis in dry-cured pork butts }\end{array}$ & Periódicos Capes & $\begin{array}{l}\text { Zhang, Xin } \\
\text { (2020) }\end{array}$ \\
\hline
\end{tabular}




\section{Resultados e Discussão}

\subsection{Diferença entre processos de secagem}

A produção de secagem da carne é desenvolvida tipicamente no Brasil como uma forma de alavancar a durabilidade e alterar as estruturas sensoriais dos produtos produzidos, através do processamento de salga, nitrito de sódio, desidratação e empacotamento, para inibir o crescimento microbiológico (Dos Santos et. al. 2017) Identificado como Q16. Segundo a Instrução Normativa $N^{\circ}$ 92, de 18 de setembro de 2020 do Ministério da Agricultura, Pecuária e Abastecimento (MAPA), formalizou a aprovação através de regulamentos técnicos de identidade de qualidade as adequações para o processamento de fabricação do charque, da carne salgada curada dessecada, do miúdo salgado dessecado e do miúdo salgado curado dessecado, assim, é possível observar uma melhor padronização nestes processos em relação ao controle de qualidade na produção destes alimentos no país. (Brasil, 2020). Embora sempre retratadas pelo mesmo nome, existem diferenças entre os processos de secagem das carnes no Brasil.

\subsubsection{Charque}

A produção de charque é formada através da salga de diversos tipos de cortes, seguido por exposição ao sol, no qual irá ocorrer uma conservação por meio da temperatura, devido ao processo que elimina o risco de desenvolvimento microbiano, considerando a retirada de umidade do produto, para isso, a carne precisa passar pelo processo de desossa, manteação, salga úmida, salga, salga seca, ressalga, pilha de volta, tombagem, lavagem, secagem e embalagem (Brasil, 2020). É válido observar que o conhecido jerked beef (JB) encontrado nos supermercados é uma versão anglo-saxã deste mesmo produto, com alteração no nome comercial, e embora sejam aparentemente semelhantes, a JB é adicionada de maiores teores de sais de cura e costuma ser encontrada a vácuo nos supermercados.

\subsubsection{Carne do Sol}

A produção de carne de sol nas regiões do Norte e Nordeste, é predominantemente artesanal, motivo esse que provavelmente, ainda não existe uma padronização no preparo, assim como não há registro no Regulamento da Inspeção Industrial e Sanitária de Produtos de Origem Animal (RIISPOA). Seu preparo é realizado através do acréscimo de sal, podendo sofrer com fatores naturais como a exposição ao sol, desidratação por ar, em condições diurnas ou noturnas. Também pode ser conhecida como diversas variações a depender do local, como carne seca, carne do sertão, carne de jabá (indígena), carne de paçoca. Estas variações podem também implicar no processamento do produto (Assis et. al. 2019) Identificado como Q6.

A carne do sol de Caicó (RN) tem forte impacto na cultura alimentar nordestina, sendo o local referência na sua produção e comercialização. Amaral et. al (2014) Identificado como Q3, utilizou da oportunidade para analisar sensorialmente atributos de sabor, aroma, cor, aparência e dureza, assim como avaliou a intenção de compra do consumidor das carnes do sol de coxão mole e alcatra vendidas nas cidades de Currais Novos e Caicó, municípios pertencentes ao Rio Grande do Norte. Os resultados obtidos demonstraram que os consumidores certamente comprariam o coxão mole de Currais Novos e a alcatra de Caicó. Dentre as 4 amostras, os avaliadores aceitaram positivamente os atributos do coxão mole de Currais Novos, com média 4 (gostei), no teste de aceitação com escala estruturada.

Sob a proposta de verificar as condições higiênico-sanitárias e tecnológica (HST) assim como a situação microbiológica e físico-química, Assis et. al (2019) Identificado como Q6 analisou a produção e comercialização das carnes do sol em Salinas, Minas Gerais, região de forte produção artesanal. Os pesquisadores coletaram 40 amostras do produzidas em comércios locais da região. Em relação aos estudo físico-químicos, foram analisados pH (5.8), cloretos (3,63\%), cinzas $(5,09 \%)$, gorduras $(2,25 \%)$, proteínas $(22,35 \%)$ e umidade $(70,13 \%)$. Foi detectado a presença de microrganismos aeróbios 
mesófilos $\left(2,50 \times 10^{7} \mathrm{UFC} / \mathrm{g}\right)$, levedura e bolores $\left(1,73 \times 10^{4} \mathrm{UFC} / \mathrm{g}\right)$ coliformes termotolerantes e totais $(9,1 \mathrm{NMP} / \mathrm{g}$ e 4,3 NMP/g). Foi confirmado a presença de Salmonella spp. em duas amostras, e 16 estavam contaminadas com Staphylococcus aureus. Em relação a HST, foi detectado que as mesas de manipulação eram construídas em pedra (ardósia ou granito), os tetos eram de madeira, e apenas um açougue apresentou forro PVC, não haviam muitos equipamentos e utensílios de aço inox. Apesar de apresentarem propostas de controles de pragas e vetores como moscas, baratas e roedores, diversos açougues não possuíam Programa de controle Integrado de Pragas e Vetores, além de não possuírem telas de proteção contra insetos nas janelas. Os resultados apresentaram respostas não satisfatórias no que diz respeito aos parâmetros microbiológicos e HST, demonstrando a necessidade de padronização na comercialização, a fim de que evite colocar em risco a saúde dos consumidores.

A carne soleada é um exemplo da grande variedade de carne seca ao redor do Brasil. Produzida similarmente a carne do sol, porém, de cunho originário e exclusivo do pantanal, este preparo é realizado tradicionalmente com o corte do coxão duro (m. biceps fermural). Alves et. al. (2010) Identificado como Q1. Sob a proposta de avaliar pH, atividade de água e teor de cloretos aplicadas a redução de microrganismos da carne soleada artesanal, e verificar técnicas de congelamento e embalamento a vácuo para analisar a redução da carga microbiana, em seus resultados puderam observar que devido a produção artesanal e de pequena escala, a carne soleada se difere da carne do sol devido ao baixo teor de $\mathrm{NaCl}$, contendo uma umidade intermediária e durando apenas 2 dias. Fatores como $\mathrm{pH}$, redução da atividade de água e teor de cloretos adicionados não foram suficientes para eliminar focos de Staphylococcus aureus e Escherichia coli encontrados na amostra utilizada. Congelamento e selagem a vácuo não apresentaram nenhuma eficácia no controle de multiplicação de microrganismos na amostra.

\subsubsection{O impacto da carne seca na história brasileira}

Segundo historiadores, acredita-se que a produção de carne seca tenha se iniciado na pré-história, quando após as caças, as carnes eram cortadas e expostas as rochas que ficavam ao sol, assim a carne absorvia os sais presentes na rocha, quando sofriam a exposição ao calor do sol. Outra teoria, seria da exposição de carnes próxima a praias, nas quais sofriam com a maresia, enquanto expostas ao sol. Embora sejam teorias, é importante observar que a técnica já era executada por indígenas nas quais seriam aprimoradas ao longo dos anos.

Sendo um dos principais alimentos presentes na alimentação dos escravos devido a sua grande disponibilidade, a charque teve grande repercussão no Recôncavo Baiano, muito consumido com farinha de mandioca, fubá, arroz e feijão, entre diversos outros legumes disponíveis. Com valor acessível, fornecia a possibilidade de reduzir custos com abates e prolongar a durabilidade das carnes para consumo e venda. A partir do século XVII, com a chegada de milhares de escravos africanos e a necessidade de suprir o mercado, foram instaladas as primeiras charqueadas na região de Pelotas (RS), no qual o estado se mantém até hoje como uma das grandes produtoras de charque (Vargas, 2017) Identificado como Q8.

A carne seca inicialmente teve sua introdução no Ceará devido a chegada dos gados dos estados de Pernambuco (PE) e Rio Grande do Norte (RN) no século XVII, tendo como apoio o Rio Jaguaribe para a criação, e devido ao crescimento da pecuária, haviam altas perdas das carnes devido ao abate para a produção e utilização do couro e considerando a não sobrevivência do gado a longas travessias e a perecibilidade da carne, instalaram-se as conhecidas oficinas ou feitorias de charqueada, que com a ajuda do clima, vento e umidade, se tornou rapidamente um negócio lucrativo e de sucesso, dando início a um novo perfil econômico e social no estado. Apesar de toda historicidade, o consumo de charque ainda consegue ser maior do Sul do país, enquanto cenário gastronômico (Frota et. al, 2016) Identificado como Q12. 


\subsubsection{Processamento, produção e preparação de charque}

O processamento do charque ocorre por meio da salga de peças de carne, sendo costumeiramente embalado a vácuo e levado para a venda enquanto alimento pré-preparado para consumo, havendo a necessidade de o consumidor realizar a retirada do sal parcialmente ou totalmente, no período de 24 a 48 horas sob refrigeração e molho. É discutido que este método de dessalga caseira possui ineficácia devido à baixa remoção de sal, modificações físico-químicas do produto, alteração microbiológica, sensorial e nutricional do produto (Bampi, et. al. 2019) Identificado como Q10.

\subsubsection{O preparo artesanal e industrializado do charque}

\subsubsection{Processos de charqueamento antigos}

O processamento de alimentos realizados de maneira artesanal, foram desenvolvidos por meio de salgas tradicionais, em casas ou charqueadas com este propósito. Acredita-se que poderia haver riscos à saúde do consumidor, devido a possíveis contaminações e deficiências higiênicas do processo. Considerando o surgimento da legislação que regulamenta a produção de charques, Santo e Hentges (2015) Identificado como Q11, desenvolveram um estudo considerando a produção de charques artesanais realizados atualmente, sob a proposta de analisar e orientar a melhoria nos processos de qualidade do insumo final. Em seus resultados, foi verificado a possibilidade da realização artesanal, desde que possua um controle dos processamentos e que atenda a legislação de Boas Práticas de Fabricação (BPF), assim como a utilização de insumos de qualidade. Os produtos analisados atenderam as exigências físico-químicas, entretanto, nas microbiológicas, era necessária uma melhoria, através de um acompanhamento de profissional de alimentos competentes para a estruturação da produção e padronização dos processos de qualidade.

\subsubsection{Processos de charqueamento modernos e os padrões de qualidade.}

A charque deve seguir rigorosos padrões de qualidade no processamento, não devendo possuir sabores e odores atípicos de carne fresca, não possuir sabor rançoso, textura pegajosa, deve estar firme e não possuir mais do que $45 \%$ de umidade por porção muscular. É tolerável uma porção de amostra indicativa de coliformes a $45^{\circ} \mathrm{C} / \mathrm{g}$, estafilococos coagulase positiva/g não deve possuir em sua composição Salmonella ssp. O fluxograma industrial do processamento do charque deve ser: recepção de matéria prima; armazenamento em câmara fria; toalete/manteação; salga úmida; salga seca; ressalga; pilhas de volta; tombagem; lavagem; secagem; embalagem/comercialização. Portanto, é necessário que as instalações, equipamentos, processos e controles de qualidade estejam adequados na indústria, para que se possa obter um produto de qualidade e padronizado (Ferreira, 2015) Identificado como Q13.

Na construção de novos processos para a produção do charque, Bampi et. al (2019) Identificado como Q10, objetivou estudar a secagem a carne por meio de vácuo por microondas e as características físico-químicas e a utilização de salmoura de $\mathrm{KCl}$ em substituição ao $\mathrm{NaCl}$. Os resultados obtidos foram de forte impacto para a construção de novas tecnologias industriais, uma vez que a secagem a vácuo por meio de microondas, possibilitou a desidratação em menor tempo que o convencional e foi observado que a mesma apresentou características de porosidades, textura esta, que facilitará a reidratação das peças. Também foi descoberto que a redução da quantidade de $\mathrm{NaCl}$ e a adição parcial de $\mathrm{KCl}$ foi viável, portanto, oferecendo um produto menos salgado e igualmente desidratado aos clientes.

\subsubsection{A tecnologia de alimentos aplicado a charque}

A aplicação de técnicas de salgas em carnes fornece fatores primordiais para a construção de diversos produtos. É possível observar na União Europeia (UE) uma grande variedade de embutidos fermentados considerados iguarias, seja em regiões mais quentes do Mediterrâneo, como em climas frios como Polônia e Alemanha. Na perspectiva da salga em alimentos, 
pode observar em três categorias distintas: com baixo teor de sal, com a possibilidade de ser consumido a qualquer momento do preparo; salgados e dessecados que incluem os que não tem necessidade de dessalgas, que podem ser conservados em temperatura ambiente por menor tempo; e as com salgas mais fortes, havendo a necessidade de dessalgar e coccionar o alimento. Os animais mais utilizados para aplicabilidade de técnicas de salga da UE costumam ser bovinos, caprinos e suínos (Santos, 2015) Identificado como Q11.

Considerando o charque uma das técnicas mais antigas para conservação de carnes, o consumo desta iguaria e as técnicas não se aplicam apenas a carne bovina, mas também para carnes como de cavalo, cervos, lhamas entre outros não convencionais. O crescimento do consumo destas carnes e as técnicas foram notadas por Willy e Faustina (2014) Identificado como Q5, no qual se propuseram a comparar características físico-químicas do charque de cavalo e o bovino, sendo um estudo importante para a comunidade científico/acadêmica, considerando que não existiam na época estudos sobre a temática. Parâmetros como: umidade, gordura, proteína, cinzas, colesterol, perfil de ácidos graxos, minerais, pH, aw e cor foram avaliados. Foi possível identificar que teores de gordura e umidade não sofreram diferenciação em ambas espécies. Ácidos graxos saturados (48,3\% e $42,7 \%)$ e monoinsaturados $(43,1 \%$ e $38,5 \%)$ foram elevados nas amostras de bovinos, assim como ácidos graxos desejáveis $(69,97 \%$ e 65,92\%). Entretanto, amostras de cavalo demonstraram-se valores elevados de ácidos graxos poli-insaturados $(18,3 \%$ vs. $17,8 \%)$. O menor teor de proteína $(68,05 \%)$ e maior teor de cinzas $(8,24 \%)$ foram identificados na carne de cavalo, entretanto, a carne bovina apresentou menor colesterol (157,50 mg/100g). O sódio (1477 mg e $2528 \mathrm{mg} / 100 \mathrm{~g}$ ) e grande parte de diversos minerais estavam mais presentes na carne de cavalo. Sobre a cor, a carne de cavalo apresentou maior luminosidade e teor de amarelecimento. Portanto, estes resultados foram importantes para observar que estas espécies não possuem muita umidade, baixa atividade de água e que os bovinos possuem menor colesterol. Em relação a ácidos graxos saturados e monoinsaturados foram encontrados maiores concentrações em bovino do que em equinos. O conteúdo de sódio se encontra em níveis moderados para consumo.

Alguns anos antes do desenvolvimento da análise da carne de cavalo, Willy e Faustina (2011) Identificado como Q4, propuseram estudar as características físico-químicas (umidade, proteínas, minerais, ácidos graxos, colesterol) da produção da carne de lhama na região de Altiplano dos Andes Centrais, produzida artesanalmente. Portanto, foram adquiridos em mercados e açougues de Oruro, na Bolívia, 20 peças de carne seca de lhama em amostras de 450 a 500g. Os resultados encontrados demonstraram que o charque de lhama possui elevados níveis de proteína $(66,12 \%)$, e baixa umidade $(19,05 \%)$ e atividade de água $(0,64)$. Rico em minerais e ácidos graxos elevados $(70,27 \%)$ saturados e insaturados, são compatíveis aos da alpaca e carne bovina seca. Possui alto nível de colesterol $(139,58 \%)$. Em comparativo, os níveis de sódio são mais baixos que o charque de alpaca e mais alto que o bovino.

\subsubsection{Processos e parâmetros de qualidade na produção de carne seca}

Buscar parâmetros de qualidade no processo de obtenção de carnes secas fornece uma visão tecnológica para a construção do conhecimento acerca da temática, considerando os processos artesanais que se mantêm tão fortes. Dall'Olio et. al (2020) Identificado como Q14, buscou compreender em seu estudo a investigação das relações fenotípicas da perda de peso de presunto maturado, relacionado com os parâmetros de qualidade na produção de presuntos de suínos. A autora observou diversos parâmetros, incluindo desempenho do processamento, da carcaça e processos de qualidade. Os resultados apontaram que é importante a utilização de animais maduros e carcaças com peso adequado para a obtenção de presuntos crus de qualidades, sendo adequados a salga e o tempero certo.

A alimentação de bovinos e a possibilidade de afetar a carne do animal para consumo foi alvo de uma pesquisa com a proposta de verificar a adição e a ausência de minerais, fosfatos, antibióticos e ionóforos. Sendo uma dieta administrada usando três dietas diferentes, uma por semana. Foi identificado que nas condições do gado brasileiro, a alimentação dos 
bovinos não requer nenhuma dieta especial, e a ausência deste foi irrelevante para garantir a qualidade da carne. (De Oliveira Lima, 2020) Identificado como Q15.

A verificação da influência de metais diferentes durante o processo de cura a seco de rabo de porco foi analisada com a realização de substituições parciais de $\mathrm{NaCl}$ por $\mathrm{KCl}, \mathrm{CaCl} 2, \mathrm{MgCl} 2$ e $\mathrm{ZnCl}$, para avaliação e controle dos testes. As propriedades físico-químicas proteólise e ensaios sensoriais foram avaliados neste estudo para melhor compreensão da padronização da salga da cura a seco e processo de melhoria de qualidade. Os resultados demonstraram que a substituição por diferentes substratos evitava a desidratação no que tange o aspecto da carne. Houve modificação significativa no pH com a adição do cálcio. Os autores identificaram que a substituição por íons metálicos demonstrou uma alternativa para a textura da carne e melhoria no sabor. Os aspectos demonstraram ser uma estratégia para a regulamentação e comercialização no quesito nutricional e funcional (Zhang et. al, 2020) Identificado como Q17.

A preocupação de manter alimentos seguros é de interesse de todos, a considerar a necessidade de manutenção da saúde coletiva, assim, Abrantes et. al. (2014) Identificado como Q2, desenvolveu um estudo para analisar a qualidade microbiológica da carne de charque industrialmente produzida seguindo parâmetros de inspeção estadual do Rio Grande do Norte, portanto, entre 2009 e 2010, foram coletadas 25 amostras de carne de charque, e dos resultados obtidos, foi possível identificar que cinco amostras (20\%) estavam desconforme a legislação da Agência Nacional de Vigilância Sanitária (ANVISA), com testagem positiva para estafilococos coagulase, as 25 carnes avaliadas (100\%) apresentaram teste positivo para coliformes termotolerantes e 7 destas amostras apresentaram resultados positivos para Salmonella spp. Portanto, os resultados apresentaram uma deficiência no controle de qualidade e Boas Práticas na Fabricação de alimentos, sendo um risco à saúde do consumidor.

O controle de qualidade também foi objeto de estudo de Souza et. al. (2015) Identificado como Q9, no qual buscou avaliar e comparar as contaminações microbiológicas de carnes bovinas utilizadas no preparo de carne do sol de diferentes locais e condições de armazenamento. Seguindo a mesma proposta do trabalho anterior, foram analisadas 15 amostras de carnes, no qual a presença de coliformes foi identificada entre $<3,0 \mathrm{NMP} / \mathrm{g}$ a $>1100 \mathrm{NMP} / \mathrm{g}$. Staphylococcus spp. teve sua presença confirmada através de variação entre 5,5 x 103 a 2,9 x 106 UFC/g. Foi identificado Escherichia coli. em 66,67\% das amostras, e Staphylococcus coagulase positiva em 26,67\%. A elevada presença de microrganismos patogênicos demonstrou deficiência no beneficiamento das carnes, o que pode acarretar surtos alimentares.

A tecnologia também busca avaliar a alteração de aroma nos alimentos, especialmente nos produtos de charque. Wen et. al. (2021) Identificado como Q7, buscou avaliar os aromas de charque inoculados com diferentes culturas de bactérias autóctones de ácido lático, sendo 4 amostras inoculados com cepas de Lactobacillus sakei BL6, Pediococcus acidilactici BP2 e Lactobacillus fermentum BL11, e 1 não inoculado como amostra controle. A proposta foi analisar as amostras por meio de utilização do equipamento e-nariz, um nariz eletrônico, capaz de identificar aromas com precisão. Nos resultados obtidos, foram identificados cerca de 42 compostos voláteis, a inoculação das cepas apresentou redução nos aldeídos responsáveis pelo auto oxidação lipídica. Foi perceptível o aumento dos níveis de ésteres na cepa $P$. acidilactici BP2, em relação ao aroma, este se diferiu dos demais. As demais cepas não apresentaram diferenças no aroma entre si e a amostra controle. As descobertas destes trabalhos visam promover diferenciações de sabores de charque, sob uma nova proposta tecnológica para a alimentação, como a definição de aromas dos charques inoculados com cepas de bactérias, e a aplicabilidade do equipamento e-nariz, como um apoio no desenvolvimento de novos produtos.

\section{Conclusão}

A produção de carne secas no Brasil demonstrou grande versatilidade e possibilidade de produção. Embora os estudos 
analisados, relacionados a comercialização deste produto, não tenham apresentando resultados positivos em relação a parâmetros microbiológicos, físico-químicos e sanitários, é possível visualizar o impacto histórico, tecnológico, e evolucionário que as carnes secas possuem, seja em aspectos que tangem sua produção ou seus parâmetros de qualidade, além de verificar um avanço no padrão de qualidade na sua produção. A construção de uma revisão sistemática dos processos e o registro científico através do estudo, mostrou-se um instrumento eficaz para compilar as nomenclaturas e diferenciar processos e produtos. Os dados obtidos nessa revisão abrem oportunidades para futuros estudos com carnes salgadas. Sugere-se que novas pesquisas sejam realizadas abordando os padrões microbiológicos das carnes secas produzidas em cada região, considerando não apenas a matéria prima, mas também os manipuladores como veículos de contaminação, garantindo a produção de carne salgada segura para a saúde do consumidor. Os processos de carnes secas devem ser padronizados através das Boas Práticas de Fabricação, a fim de manter a segurança na produção de alimentos e entregar um produto de qualidade e seguro ao consumidor.

\section{Referências}

Abrantes, M. R., Sousa, A C. P., Araújo, N. K. S., Sousa, E. S., Oliveira, A. R. M. \& Silva, J. B. A. (2014). Avaliação microbiológica de carne de charque produzida industrialmente.Arq. Inst. Biol. São Paulo. 81(3), 282-285.

Alves, L. L., Delbem, A. C. B., Abreu, U. G. P. \& Lara, J. A. F. (2010). Avaliação física-química e microbiológica da carne soleada do pantanal. Ciência e tecnologia de alimentos. ISSN 0101-2061.

Alves, G., Zabine, L., Bantle, J. F., Rodrigues, L. C. S., Pasquali, R. \& Nascimento, I. A. (2010). Avaliação Físico-Química, Microbiológica e Sensorial de Tilápias do Nilo (Oreochromis niloticus) Inteiras Evisceradas Submetidas a Salga e Secagem Natural. Arq. Ciênc. Vet. Zool. UNIPAR, Umuarama. 13(2), 7175 .

Amaral, D. S., Cardoso, D. S. G. \& Pessoa, T. (2014). Avvaliação sensorial da carne de sol comercializada nas cidades de caicó e currais novos. Holos, 1, 136142. doi:https://doi.org/10.15628/holos.2014.897

Assis, D. C. S., Santos, T. M., Ornellas, C. B. D., Drummond, A. F., Magalhães, F. C. \& Santos, W. L. M. (2019). Caracterização microbiológica, físicoquímica e das condições de produção e comercialização da carne de sol de Salinas, Minas Gerais. Arquivo Brasileiro de Medicina Veterinária e Zootecnia. $71(6), 1678-4162$

Bampi, M., Schmidt, F.C. \& laurindo, J.B. (2019). Vacuum-aided production of low sodium ready-to-eat charque. J Food Sci Technol. 56(8), 3579-3586. doi: $10.1007 / \mathrm{s} 13197-019-03729-2$

Bertolin, T. E., Margarites, A. C. F., Giacomelli, B., Fruetti, A., Horts, C. \& teixeira, D. M. F. (2011). Ficocianina, tocoferol e ácido ascórbico na prevenção da oxidação lipídica em charque. Braz. J. Food Technol., Campinas. 14(4), 301-307. doi: https://doi.org/10.4260/BJFT2011140400036.

BRASIL (2020). Ministério da Agricultura, Pecuária e Abastecimento. Instrução normativa $\mathrm{N}^{\circ} 92$ de 18 de setembro de 2020 . Brasília, DF.

Campêlo. M. C. S., Medeiros, J. M. S., Rebouças, M. O. \& Silveira, C. (2017). Use of natural preservatives in low sodium carne de sol beef. e101111.

Carina dos Santos, J., Messias BuenO, S. \& Barbosa de Almeida, C. (2017). Avaliação dos métodos de conservação de carnes bovinas salgadas e análise microbiológica. 1(1)

Carvalho jr, B. C. (2002). Estudo da evolução das carnes bovinas salgadas no Brasil e desenvolvimento de um produto de conveniência similar a carne-de-sol. 265p. Tese (doutorado) - Universidade Estadual de Campinas, Faculdade de Engenharia de Alimentos, Campinas, SP.

Cas, M. R. D. (2010). Implantação de boas práticas de fabricação (BPF) em indústria beneficiadora de erva-mate. 136 f. Dissertação (Mestrado em Ciência e Tecnologia de alimentos) - Centro de ciências rurais. Universidade Federal de Santa Maria, Santa Maria.

Correia, R. T. P. \& Biscontini, T. M. B. (2003). Influência da dessalga e cozimento sobre a composição química e perfil de ácidos graxos de charque e jerkedbeef. Ciência e Tecnologia de Alimentos. 23(1) 38-42.

Dall'Olio, S., Aboagye, G., Nanni Costa, L., Gallo, M. \& Fontanesi, L. (2019). Effects of 17 performance, carcass and raw ham quality parameters on ham weight loss at first salting in heavy pigs, a meat quality indicator for the production of high quality dry-cured hams. Meat Sci. e108012.

Oliveira Lima, L., Souza, V. C., Messana, J. D., Castagnino, P. S., Lima, A. R. C. \& Berchielli, T. T. (2020). Phosphorus supplementation does not affect the intake, digestibility, and meat quality of Nellore young bulls fed with high-grain diets. Acta Scientiarum. Animal Sciences, vol. 43.

Santos, C. J. M. B. S. \& De Almeida, C. B. (2017). Avaliação dos métodos de conservação de carnes bovinas salgadas e análise microbiológica. Rer. Cientifica. 1(1).

Fernandes, F. P., Voloski, F. L. S., Ramires, T., Haubert, L., Reta, G. G., Mondadori, R. G., Silva, W. P., Conceição, R. C. S. \& Duval, E. H. (2017). Virulence and antimicrobial resistance of salmonella spp. And escherichia coli in the beef jerky production line. e101093. 
Ferreira, M. C. (2015). Implantação das boas práticas de fabricação na indústria de charque. 35 f. Trabalho de Conclusão de Curso (Especialização) Universidade Federal do Rio Grande do Sul.

Freitas, J. M. A., Higuchi, L. H., Feiden, A., Maluf, M. L. F., Dallagnol, J. M. \& Boscolo, W. R. (2011). Salga seca e úmida de flés de pacu (Piaractus mesopotamicus). Ciências Agrárias, Londrina, 32(2), 613-620.

Frota, L. F. R. \& Gondim N. L. (2016). Charqueada: A História da carne de sol no Ceará e sua frota do Icó ao Aracati. Revista de encontros universitários da UFC. v. 1 n. 1.

Han, G., Chen, Q., Xia, X., Liu, Q., Kong, B. \& Wang, H. (2021). High hydrostatic pressure combined with moisture regulators improves the tenderness and quality of beef jerky. Meet sci. e108617.

Ishiara, Y. M. \& Madruga, M. S. (2013). Indicadores de Maciez em Carnes Salgadas e Dessecadas: uma revisão. Semana: Ciências Agrárias, Londrina, 34(6) $3721-3738$

Kim, H. J., Jung, S. \& Yong, H. I. (2014).Improvement of microbiological safety and sensorial quality of pork jerky by electron beam irradiation and by addition of onion peel extract and barbecue flavor. Radiation physics and chemistry. (9) 22-28. e101016.

Lima, L. O., Souza, V. C., Messana, J. D., Castagnino, P. S., Lima, A. R. C. \& Berchielli, T. T. (2020). Phosphorus supplementation does not affect the intake, digestibility, and meat quality of Nellore young bulls fed with high-grain diets. Acta Scientiarum. Animal Sciences, vol. 43.

Lira, G. M. \& Shimokomaki, M. (1998). Parâmetros da qualidade da carne de sol e dos charques. Revista Higiene Alimentar, 12(58), 33-35.

Linares, W. M. \& Cayo, F. (2011). Características físicas-químicas do charqui de lhama. Ver. investg. vet. Perú. 22(4). INSS $1609-9117$.

Linares, W. M \& Cayo, F. (2014). Características fisicoquímicas de charque de bovinos (bos taurus) e caballo (equus caballus). Journal of the selva andina animal science. ISSN 2311-2581.

Linde, K. \& willich, S. N. ( 2003). How objective are systematic reviews? Differences between reviews on complementary medicine. Journal of the Royal Society of Medicine, 96(1)17-22.

Nogueira, M. (2016). Qual a diferença entre carne do Sol e carne seca. Saúde. In: Super Interessante (Revista Eletrônica). Ed. Abril.

Osório, H. (2007). O império português no sul da America: estancieiros, lavradores e comerciantes. $1^{\text {a }}$ Ed. Editora: Instituto de Filosofia e Ciências Humanas da UFRS, Porto Alegre, RS.

Pardi, M. C, et al. (1996). Ciência, higiene e tecnologia da carne. Goiânia: UFG. e1110.

Pardi, M. C., Santos, I. F., Souza, E. R. \& Pardi, H. S. (1994). Ciência, Higiene e Tecnologia da Carne Goiânia: Universidade Federal de Goiás. v. 2.

Sabadini, E., Hubinger, M. D., Sobral, P. J. A. \& Carvalho Jr, B. C. (2001). Alterações da atividade de água e da cor da carne no processo de elaboração da carne salgada desidratada. Ciênc. Tecnol. Aliment., Campinas, 21(1), 14-19.

Santos, A. M. L. D. \& Hentges, L. C. (2015). Avaliação físico - química e microbiológica de carne seca (charque). Trabalho de Conclusão de Curso (Graduação) - Universidade Tecnológica Federal do Paraná, Medianeira.

Souza, D. R., Jesus, C. A., Almeida, A. C., Souza, R. M. \& Raidan, F. S. S. (2015). Qualidade microbiológica de cortes cárneos utilizados para elaboração de carne de sol no norte de minas gerais submetidos a diferentes tecnologias de conservação. Revista brasileira de ciência veterinaria. 22(1) 3-4.

Vargas, J. M. (2014). Abastecendo plantations: A inserção do charque fabricado em Pelotas (RS) no comércio atlântico das carnes e a sua concorrência com os produtores platinos (século XIX). História (São Paulo). 33(2), 540-566.

Vargas, J. M. (2017). O mercado atlântico das carnes secas e salgadas e a influência da matriz irlandesa de fabricação no extremo sul da américa latina 1780 1820. 24(45) 153-182.

Wen, R., Kong, B., Yin, X., Zhang, H. \& Chen, Q. (2021). Characterisation of flavour profile of beef jerky inoculated with different autochthonous lactic acid bacteria using electronic nose and gas chromatography-ion mobility spectrometry. Meat science. vol 183. e108658.

Xin Zhang., Junna Yang., Hang Gao., Yan Zhao., Jing Wang. \& Shouwei Wang. (2020). Substituting sodium by various metal ions affects the cathepsins activity and proteolysis in dry-cured pork butts, Meat Science, Volume 166, e108132, ISSN 0309-1740.

Youssef, E. Y. \& Garcia, C. E. (2003). Rocha and Shimokomaki, MassamiEffect of salt on color and warmed over flavor in charqui meat processing. Brazilian Archives of Biology and Technology. 46(4). ISSN 1678-4324.

Zhang, X.. Jun, Y., Hang, G., Yan, Z., Jing, W. \& Shouwei, W. (2020). Substituting sodium by various metal ions affects the cathepsins activity and proteolysis in dry-cured pork butts, Meat Science, Volume 166, e108132, ISSN 0309-1740. 